\title{
Hemangioma with Phleboliths in the Floor of the Mouth Presenting as a Submental Swelling: A Case Report
}

\author{
Yuh Baba ${ }^{\mathrm{a}, \mathrm{c}}$, Yasumasa Kato ${ }^{\mathrm{b}}$
}

\begin{abstract}
A painless, soft swelling in the submental area usually indicates the presence of a thyroglossal duct cyst, congenital sublingual dermoid cyst, amyloidosis, ranula, or cystic hygroma. We described a case of relatively rare hemangioma with multiple phleboliths in the floor of the mouth presenting as a submental swelling. We report a case of 17-year-old Japanese female who presented with the mass in the submental region that had been slowly growing for several years. The doppler ultrasonography revealed blood flow in the region. Computed tomography (CT) showed several round calcified foci, and magnetic resonance imaging (MRI) revealed a $20 \times 45 \mathrm{~mm}$ lesion in the floor of the mouth. The lesion had high intensity on T2weighted images and isointensity with muscle on T1-weighted images. Therefore, preoperative diagnosis has truly been established, although hemangioma with multiple phleboliths in the floor of the mouth presenting as a submental swelling is relatively rare.
\end{abstract}

Keywords: Hemangioma; Phlebolith; Floor of the mouth; Submental swelling; Imaging

\section{Introduction}

A painless, soft swelling in the submental area usually indicates the presence of a thyroglossal duct cyst, congenital sublingual dermoid cyst [1], amyloidosis [2], ranula [3], cystic hygroma, etc.

\footnotetext{
Manuscript accepted for publication December 16, 2010
a Department of Otolaryngology, Ohtawara Red Cross Hospital, 2-7-3 Sumiyoshi-cho Ohtawara City, Tochigi 324-8686, Japan
${ }^{\mathrm{b}}$ Department of Oral Function and Molecular Biology, Ohu University, 31-1 Misumido Tomita-machi Koriyama City, Fukushima 963-8611, Japan
${ }^{\mathrm{c}}$ Corresponding author: yuh_baba@hotmail.com

doi: $10.4021 / \mathrm{jmc} 108 \mathrm{w}$
Hemangioma is a relatively common lesion in the head and neck region. Changes in blood flow dynamic within hemangioma result in thrombus and phleboliths [4]. Phlebolith formation reported as a characteristic feature of hemangioma was first described in the splenic vein [5]. Although hemangioma is a relatively common lesion in the head and neck region, it is rarely associated with phlebolith in the region. Some cases have been reported on the hemangioma with phlebolith in buccal mucosa [6], the parotid and submandibular glands [7], and mentalis muscle [8]. However, clinical information of the hemangioma with phlebolith in the floor of the mouth presenting as a submental swelling has still been limited [9].

Here, we show a relatively rare case of a hemangioma with multiple phleboliths in the floor of the mouth presenting as a submental swelling.

\section{Case Report}

A 17-year-old Japanese female patient visited the Department of Otorhinolaryngology due to swelling of her submental region, which had been present for 4 years and had gradually increased in size without any pain.

Clinical examination showed a painless and soft swell-

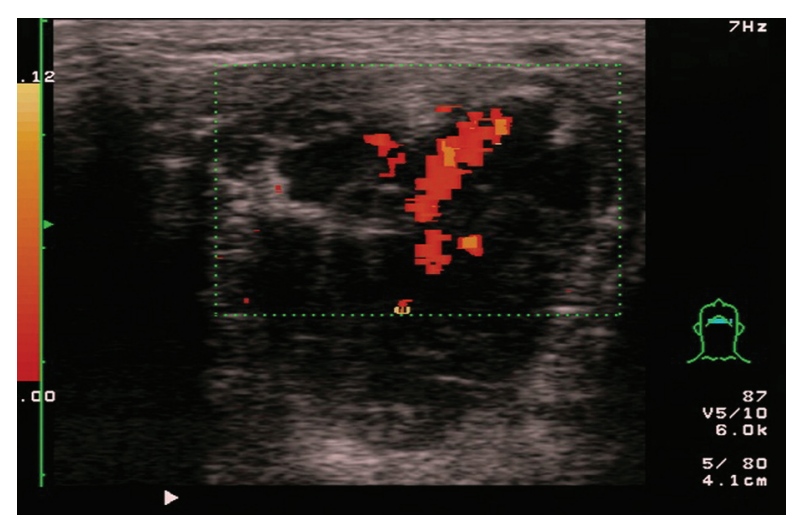

Figure 1. The doppler ultrasonography revealed blood flow in the floor of the mouth. 


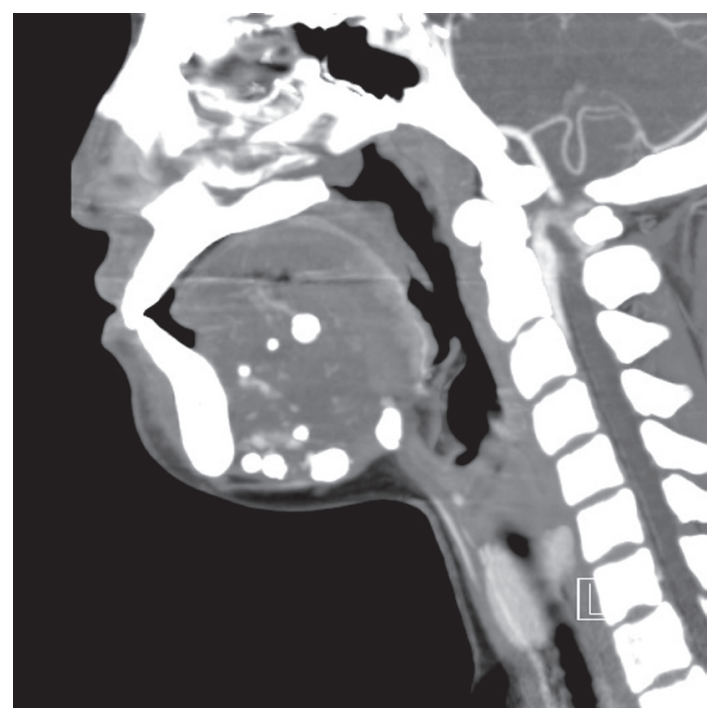

Figure 2. CT showed several round calcified foci.

ing of the submental region. The doppler ultrasonograpy revealed blood flow in this region (Fig. 1). Computed tomography (CT) showed several round calcified foci (Fig. 2) and magnetic resonance imaging (MRI) revealed a $20 \times 45$ $\mathrm{mm}$ lesion in the floor of her mouth (Fig. 3). The lesion had high intensity on T2-weighted images and isointensity with muscle on T1-weighted images. Calcification was not demonstrated on MRI. From these observations, as the preoperarive diagnosis, we considered hemangioma with phleboliths in the floor of the mouth and this region was removed by surgical operation. The surgery was performed under general anesthesia and several hard bodies within the mass were

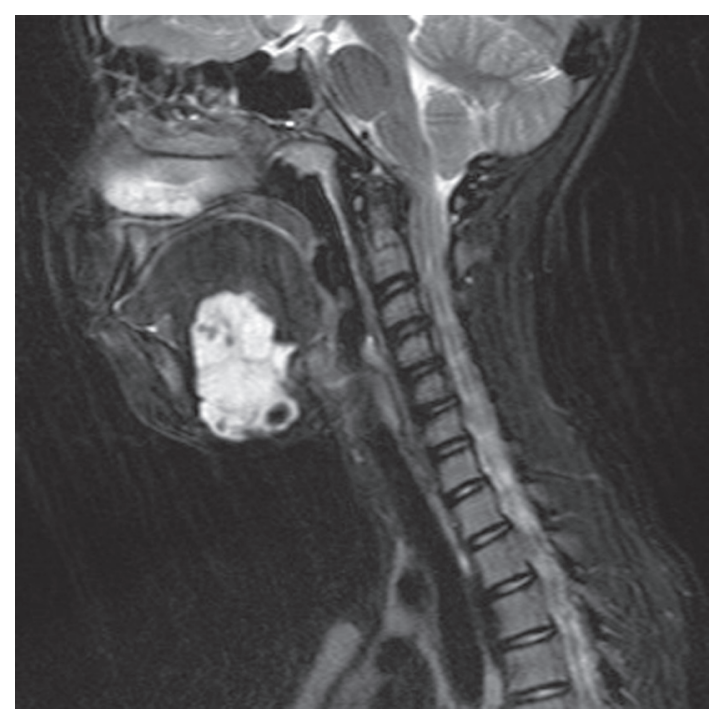

Figure 3. MRI revealed that the mass had high intensity on T2-weighted images.

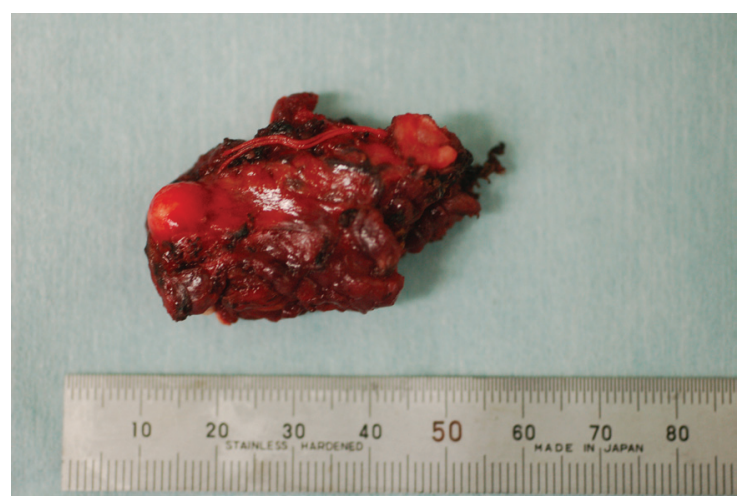

Figure 4. Several phleboliths within the mass were observed.

observed (Fig. 4). Blood transfusion was not needed and no complications occurred.

Pathological analysis showed typical feature of hemangioma (Fig. 5). Because we found phleboliths and thrombus in hemangioma, we diagnosed this case as cavernous hemangioma with phleboliths in the floor of the mouth in accordance with preoperative diagnosis.

\section{Discussion}

The most common causes of painless masses in the sublingual or submental regions are thyroglossal duct cyst, congenital sublingual dermoid cyst [1], amyloidosis [2], ranula [3], and cystic hygroma.

Phleboliths imaged as opacities in radiological examinations are among the characteristic properties of cavernous hemangioma with phleboliths. There have been a number of reports of hemangioma with phlebolith of the parotid and submandibular glands [7]. However, Hemangioma with phlebolith in the floor of the mouth is rarely reported [9].

Diagnosis for the benign tumors of mesenchymal origin such as hemangioma that involve floor of the mouth is difficult [9]. In plain radiographies, calcified structures such as phleboliths will be seen as opacities. However, plain radiographies are reported to be not always helpful in distinguishing between sialolithiasis and phleboliths as in the case reported by Dempsey and Murley [5]. Ultrasonography and $\mathrm{CT}$ are generally able to indicate the location and extent of the mass. In MRI, high intensity has been reported on T2weighted images, and isointensity with muscle has been described with T1-weighted images. Enlarged vessels may be seen as signal voids within and around lesions. However, imaging seems to have limit. For example, in the case reported by McMenamin et al [7], panoramic radiography showed multiple calcific foci in the region of the right submandibular gland, and by $\mathrm{CT}$ the case was diagnosed as chronic sialadenitis associated with salivary calculi because it was intrag- 


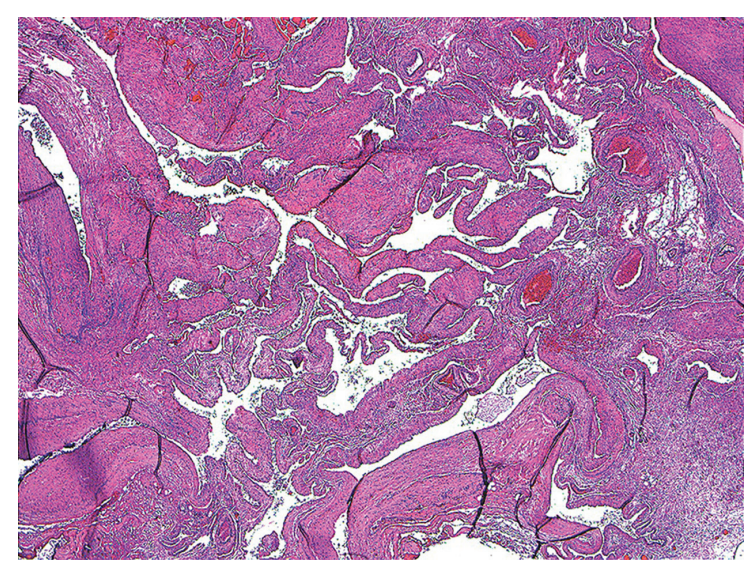

Figure 5. Microscopically, specimen demonstrated hemangio$m a$ in the floor of the mouth (H\&E, x 20).

landularly localized. Nevertheless, the result of its pathology was hemangioma with phleboliths. Furthermore, Cankaya et al [9] reported that neither MRI nor CT was sufficient for diagnosis of hemangioma with phleboliths in the sublingual gland as in the case of McMenamin et al [7]. In our case, hemangioma was localized in the floor of the mouth except the sublingual gland, and CT showed several round calcified foci. The lesion was seen clearly on T2-weighted images, and the doppler ultrasonography revealed blood flow in the region. Therefore, these observations were sufficient to diagnose our case, and actually our preoperative diagnosis was in accordance with pathological diagnosis.

In conclusion, hemangioma with phleboliths should be considered in the differential diagnosis of submental swelling and the combination with CT, MRI, and doppler ultrasonography is an important investigation method in the evaluation of lesions localized in the submental areas.

\section{References}

1. Obiechina AE, Arotiba JT, Ogunbiyi JO. Coexisting congenital sublingual dermoid and bronchogenic cyst. Br J Oral Maxillofac Surg 1999;37(1):58-60.

2. Jonsson V, Rasmussen N, Juhl BR, Gimsing P, Vorstrup S. Combined bilateral submandibular and sublingual swelling, macroglossus, and carpal tunnel syndrome caused by light chain amyloidosis. Ear Nose Throat J 1998;77(2):95-98, 100-101.

3. Ichimura K, Ohta Y, Tayama N. Surgical management of the plunging ranula: a review of seven cases. J Laryngol Otol 1996;110(6):554-556.

4. Li X. Rare cavernous haemangioma of the hypopharynx with numerous phleboliths. J Laryngol Otol 1990;104(3):262-263.

5. Dempsey EF, Murley RS. Vascular malformations simulating salivary disease. Br J Plast Surg 1970;23(1):7784.

6. Sano K, Ogawa A, Inokuchi T, Takahashi H, Hisatsune $\mathrm{K}$. Buccal hemangioma with phleboliths. Report of two cases. Oral Surg Oral Med Oral Pathol 1988;65(2):151156.

7. McMenamin M, Quinn A, Barry H, Sleeman D, Wilson $\mathrm{G}$, Toner M. Cavernous hemangioma in the submandibular gland masquerading as sialadenitis: case report. Oral Surg Oral Med Oral Pathol Oral Radiol Endod 1997;84(2):146-148.

8. Ingalls GK, Bonnington GJ, Sisk AL. Intramuscular hemangioma of the mentalis muscle. Oral Surg Oral Med Oral Pathol 1985;60(5):476-481.

9. Cankaya H, Unal O, Ugras S, Yuca K, Kiris M. Hemangioma with phleboliths in the sublingual gland: as a cause of submental opacity. Tohoku J Exp Med 2003;199(3):187-191. 